\title{
The expression profile of Jagged1 and Delta-like 4 in hepatocellular carcinoma
}

\author{
Areerat Kunanopparat, ${ }^{1}$ Nattiya Hirankarn, ${ }^{1}$ Jiraphorn Issara-Amphorn, ${ }^{1}$ Pisit Tangkijvanich, ${ }^{2}$ Anapat Sanpavat ${ }^{3}$
}

\begin{abstract}
Background: Notch signaling has been linked to many cancers. However, there is still limited information about the expression and role of the Notch ligand in hepatocellular carcinoma (HCC).
\end{abstract}

Objective: To investigate the expression of JAG1 and DLL4 in HCC tissues.

Methods: One hundred and forty-five HCC tissues in paraffin block since 2009 to 2016 at King Chulalongkorn Memorial hospital were assayed for JAG1 and DLL4 by immunohistochemistry. All the sections were separately analyzed in tumor and adjacent non-tumor tissue and scoring based on intensity and quantity of immunoreaction. Kruskal-Wallis $\mathrm{H}$ test examined the correlation between JAG1 and DLL4 protein expression and clinical pathology.

Results: The expression of JAG1 and DLL4 of tumor cells is $57.2 \%(83 / 145)$ and $88.9 \%(129 / 145)$, respectively. The expression of JAG1 is significantly higher in tumor tissues than adjacent non-tumor tissues $(P=0.002)$, and significantly increased in patients with age $<60$ years old $(P=0.007)$. Interestingly, the DLL4 expression is also expressed in the normal liver tissue and DLL4 expression is not associated with any of the clinical parameters. When we performed a subgroup analysis, in HCC patients without a viral infection analysis, JAG1 is significantly increased in HCC patients with low albumin level $(\leq 3.5)(P=0.043)$.

Conclusions: JAG1 expression is increased in HCC and seems to correlate with HCC patients with earlier onset and lower albumin level, whereas DLL4 expression did not significantly correlate with any clinical features.

Key words: Notch signaling, JAG1, DLL4, hepatocellular carcinoma, immunohistochemistry

\section{From:}

${ }^{1}$ Center of Excellence in Immunology and Immune Mediated Diseases, Department of Microbiology, Faculty of Medicine, Chulalongkorn University, Bangkok, Thailand

${ }^{2}$ Research Unit of Hepatitis and Liver Cancer, Department of Biochemistry, Faculty of Medicine, Chulalongkorn University, Bangkok, Thailand

Department of Pathology, Faculty of Medicine,

Chulalongkorn University, Bangkok, Thailand

\section{Introduction}

Hepatocellular carcinoma (HCC) is one of the most common causes of cancer death with the incident rate of nearly the same as the mortality rate due to very poor prognosis and high rate of recurrence. ${ }^{1}$ Viral hepatitis (HBV or HCV), alcoholism and prolonged cholestasis are the major risk factors for liver disease that leads to the progression of cirrhosis, which is present in 80 to $90 \%$ of patients with HCC. ${ }^{2}$ Currently, sorafenib is the main drug that uses for advanced HCC patients treatment, it can only delay median of survival approximately three months longer. ${ }^{3}$ Therefore, the new

\section{Corresponding author:}

Nattiya Hirankarn

Center of Excellence in Immunology and Immune Mediated Diseases

Department of Microbiology, Faculty of Medicine,

Chulalongkorn University, Bangkok, 10330 Thailand

E-mail: Nattiya.H@chula.ac.th

knowledge of the target molecules as well as biomarkers that associate with improve prognosis and benefit of therapy is still needed.

Notch signaling is an evolutionally conserved pathway that regulates cell proliferation, cell differentiation, apoptotic programs, and cell fate decision. Notch is comprising of Notch receptor (Notch1, 2, 3, 4) and Notch ligand (Delta-like (DLL) 1, 3, 4 and Jagged (JAG) 1, 2). Notch activation initiates when Notch ligand from signaling cell bind to Notch receptor of receiving cell that induces metalloproteinase and 
gamma-secretase enzymes to cleave Notch extracellular domain and Notch intracellular domain, respectively. The reaction releases intracellular domain of Notch receptor (ICN) and then, translocation to the nucleus for regulation of target genes such as hairy/enhancer-of-split (HES) and HEY related transcription factors. ${ }^{4}$ Due to the Notch functions in controlling the fate of cells, it is not surprising that deregulation of Notch signaling is involved in many types of cancers for tumor progression. ${ }^{5}$

Recent studies have shown that Notch inhibition is a therapeutic target for cancer treatment. Mainly, Notch ligands and Notch signaling were shown to be overexpressed and correlated with poor clinical manifestation in various cancers. In addition, gamma-secretase inhibitors (GSIs) and monoclonal antibodies (mAbs) against Notch receptor or Notch ligand blocking Notch signaling were used in a number of clinical trials such as in T-cell acute lymphoblastic leukemia, breast cancer, pancreatic cancer, melanoma and colorectal cancer. ${ }^{6}$ It should be noted that some studies suggested that Notch might act as tumor suppressive as well. ${ }^{7}$ In liver tissue, the role of Notch is still controversy. Previous data reported that human liver tissue could express all the Notch receptors (Notch1, 2, 3 and 4). ${ }^{8}$ Both DLL4 and JAG1 are the main Notch ligands expressed in the liver tissue whereas JAG2, DLL1, and DLL3 are undetectable. ${ }^{9}$ One of the main interest in DLL4 and JAG1 function is their role towards endothelial cells in promoting tumor-associated angiogenesis. ${ }^{10}$ However, there is still limited information about the expression and role of the Notch ligand in hepatocellular carcinoma cells. In this study, we investigated the expression profile of DLL4 and JAG1 in hepatocellular carcinoma and nontumorous hepatocytes tissues by immunohistochemistry and analyze the association with clinical parameters.

\section{Materials and Methods \\ Patient specimens}

One hundred and forty-five formalin-fixed, paraffin-embedded HCC tissues at King Chulalongkorn Memorial hospital, from 2009 to 2016 were taken. All HCC tissue samples and corresponding noncancerous liver tissue samples were obtained from patients who had undergone surgical hepatectomy or liver biopsy. Clinical data, including sex, age, tumor differentiation, tumor size, HBV or HCV viral infection, albumin, total bilirubin, AFP, and metastasis were collected. The study was approved by the Institutional Review Board (IRB 385/58) of the Faculty of Medicine, Chulalongkorn University.

\section{Immunohistochemistry}

Indirect immunoperoxidase staining was carried out on four-micrometer-thick sections using an automated stainer (Ventana Benchmark LT, Tucson, USA). All tissue sections were cut by the same technologist using the same microtome. All steps of the immunostaining procedure were performed in a closed system using identical settings between runs, in order to maintain consistency in immunostaining. This system included blocking with normal serum of the same species as the primary antibody, prior to application of the primary antibody. Primary antibodies included a polyclonal DLL4 antibody (sc-18640, Santa Cruz Biotechnologies; CA, USA a dilution of 1:200), and a polyclonal JAG1 antibody (sc-6011, Santa Cruz Biotechnologies; CA, USA at a dilution of $1: 100)$. The detection was done by the Ventana Ultraview technology that uses a multimeric secondary reagent. The negative control by omission the primary antibody was included.

\section{Evaluation of immunostaining and Statistical analysis}

The scoring was based on intensity and extensity. The HCC samples and corresponding noncancerous liver tissue samples were scored separately. The percentage of positive tumor and non-tumor cells was determined quantitatively by assessing the whole section. The intensity of immunostaining was determined as 0 (negative staining), 1 (weakly positive staining), 2 (moderately positive staining), and 3 (strongly positive staining). The immunoreactive score of each section was calculated by sum of these two parameters. A total score was finally calculated and grade as an expression score negative, weak (I), moderate (II), strong (III). Kruskal-Wallis $\mathrm{H}$ test examined the correlation between JAG1 and DLL4 protein expression and clinical pathology. All statistical analyses were performed using the SPSS version 17.0 software package (SPSS Inc., Chicago, IL, USA). P-values less than 0.05 were considered statistically significant.

\section{Results}

\section{JAG1 and DLL4 expression in hepatocellular carcinoma}

The expression of JAG1 and DLL4 could be detected in $57.2 \%(83 / 145)$ and $88.9 \%(129 / 145)$ in the hepatocellular carcinoma tissues, respectively. We observed that these two ligands mainly expressed in the cytoplasm of tumor cell (Figure 1). As for the expression level of JAG1, 23 cases (15.9\%) of expression score I, 30 cases (20.7\%) of expression score II, 30 cases $(20.7 \%)$ of expression score III, 62 cases $(42.7 \%)$ of negative immunoreactivity were observed in the tumors. The expression level of DLL4 in tumor cells could be categorized as expression score I in 31 cases $(21.4 \%)$, expression score II in 36 cases $(24.8 \%$, expression score III in 62 cases $(42.8 \%)$, and negative immunoreactivity in 16 cases $(11.0 \%)$.

Out of 145 samples, we were able to investigate the expression pattern in the adjacent non-tumor tissues in 93 cases. Low-level expression of JAG1 (expression score 0-I) was observed in adjacent non-tumor tissues. The expression of JAG1 was significantly higher in tumor tissues than adjacent non-tumor tissues $(P=0.002)$ (Table 1). However, the expression level of DLL4 was significantly lower in tumor tissues than adjacent non-tumor tissues $(P<0.001)$ (Table 1$)$. The expression level of DLL4 in adjacent non-tumor cells could be seen as an expression score I in 11 cases (11.8\%), expression score II in 17 cases (18.3\%), expression score III in 64 cases $(68.8 \%)$, and only 1 case as negative immunoreactivity. Interestingly, it should be noted that the pattern of immunoreaction of DLL4 in tumor tissue is different from adjacent non-tumor tissues (Figure 1). 


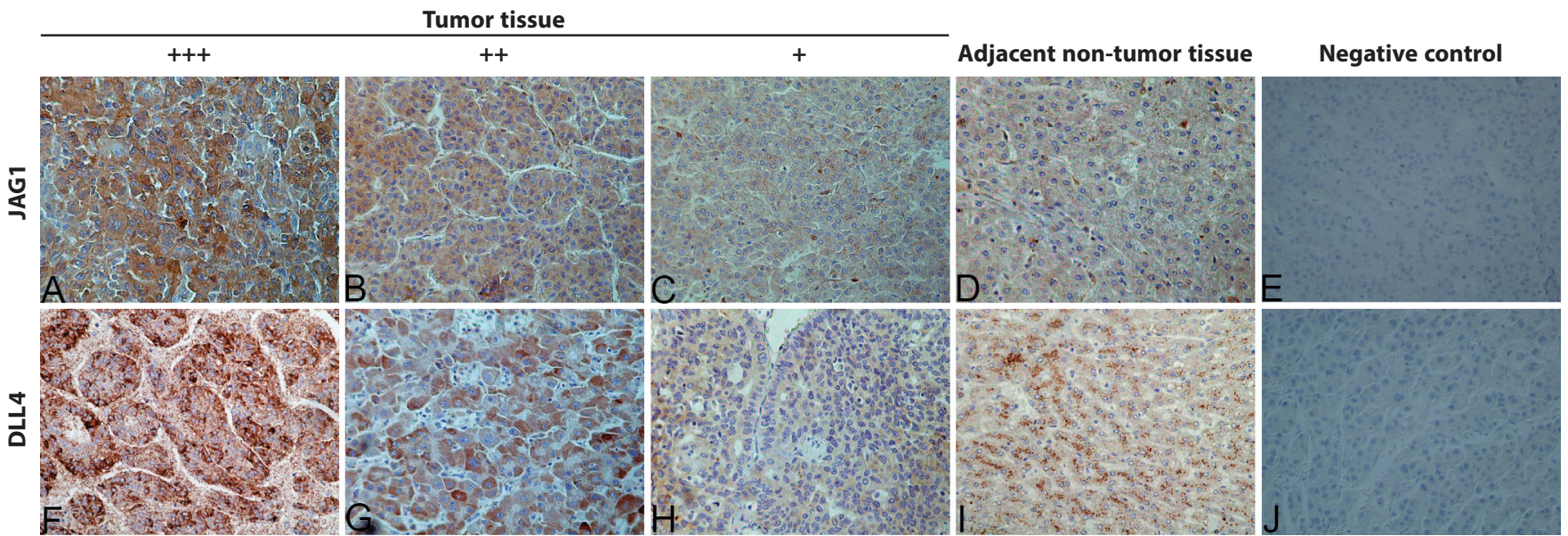

Figure 1. The immunoreaction of JAG1 (A-E) and DLL4 (F-J) in the cytoplasm of hepatocellular carcinoma and adjacent non-tumor liver tissue $(\mathrm{D}, \mathrm{I})$. The intensity of immunostaining was determined as strongly positive staining (A, F), moderately positive staining $(\mathrm{B}, \mathrm{G})$, weakly positive staining $(\mathrm{C}, \mathrm{H})$ and the negative control $(\mathrm{E}, \mathrm{J})($ Original magnification, $\times 200)$.

Table 1. The expression level of DLL4 and JAG1 in hepatocellular carcinoma and adjacent non-tumor tissue.

\begin{tabular}{|c|c|c|c|c|c|c|}
\hline & \multirow{2}{*}{$n$} & \multicolumn{4}{|c|}{ Score (\%) } & \multirow{2}{*}{$P$ value } \\
\hline & & - & + & ++ & +++ & \\
\hline DLL4 & & & & & & $<0.001$ \\
\hline HCC & 145 & $16(11.0)$ & $31(21.4)$ & $36(24.8)$ & $62(42.7)$ & \\
\hline Adjacent non-tumor tissue & 93 & $1(1.0)$ & $11(11.8)$ & $17(18.3)$ & $64(68.8)$ & \\
\hline JAG1 & & & & & & 0.002 \\
\hline HCC & 144 & $62(43.0)$ & $23(16.0)$ & $29(20.1)$ & $30(20.8)$ & \\
\hline Adjacent non-tumor tissue & 104 & $64(61.5)$ & $18(17.3)$ & $15(14.4)$ & $7(6.7)$ & \\
\hline
\end{tabular}

-, Negative staining; +, weakly positive staining; ++ , moderately positive staining; +++ , strongly positive staining.

\section{The association of JAG1 and DLL4 with clinicopathological} parameters

The JAG1 expression is significantly increased in patients with age $<60$ years old $(P=0.007)$ but not with any other clinical parameters (Table 2). The DLL4 expression is not associated with clinical parameters such as sex, age, tumor differentiation, tumor size, $\mathrm{HBV}$ or $\mathrm{HCV}$ viral infection, albumin, total bilirubin, AFP, cirrhosis, and metastasis. However, there was a trend of association between DLL4 expression and viral infection $(P=0.065)$. Therefore, we sub-analyzed data based on viral infection. In HCC patients without a viral infection analysis, JAG1 is significantly increased in HCC patients with low albumin level $(\leq 3.5)(P=0.043)$ (Table 3). In HCC patients with a viral infection analysis, there was no significant difference between a clinical parameter and JAG1 or DLL4 expression (data not shown).

Table 2. Correlation between expression of DLL4 and JAG1 and clinicopathological parameters in HCC patient.

\begin{tabular}{|c|c|c|c|c|c|c|c|c|c|c|c|}
\hline \multirow{2}{*}{ Total $(n=145)$} & \multirow{2}{*}{$n$} & \multicolumn{4}{|c|}{ DLL4 } & \multirow{2}{*}{$P$ value } & \multicolumn{4}{|c|}{ JAG1 } & \multirow{2}{*}{$P$ value } \\
\hline & & - & + & ++ & +++ & & - & + & ++ & +++ & \\
\hline Age (yr) & & & & & & 0.671 & & & & & $0.007^{* * *}$ \\
\hline$\leq 60$ & 70 & 7 & 15 & 19 & 29 & & 23 & 11 & 16 & 20 & \\
\hline$>60$ & 76 & 9 & 16 & 17 & 34 & & 39 & 12 & 14 & 10 & \\
\hline Gender & & & & & & 0.645 & & & & & 0.574 \\
\hline Male & 124 & 12 & 29 & 31 & 52 & & 52 & 18 & 29 & 25 & \\
\hline Female & 22 & 4 & 2 & 5 & 11 & & 10 & 5 & 1 & 5 & \\
\hline
\end{tabular}


Table 2. (Continued)

\begin{tabular}{|c|c|c|c|c|c|c|c|c|c|c|c|}
\hline \multirow{2}{*}{ Total $(n=145)$} & \multirow{2}{*}{$n$} & \multicolumn{4}{|c|}{ DLL4 } & \multirow{2}{*}{$P$ value } & \multicolumn{4}{|c|}{ JAG1 } & \multirow{2}{*}{$P$ value } \\
\hline & & - & + & ++ & +++ & & - & + & ++ & +++ & \\
\hline Tumor size $(\mathrm{cm})$ & & & & & & 0.471 & & & & & 0.516 \\
\hline$\leq 5$ & 59 & 7 & 13 & 12 & 27 & & 28 & 9 & 11 & 12 & \\
\hline$>5$ & 65 & 9 & 14 & 18 & 24 & & 24 & 12 & 13 & 13 & \\
\hline Differentiation & & & & & & 0.473 & & & & & 0.834 \\
\hline Well & 36 & 5 & 3 & 9 & 19 & & 13 & 6 & 7 & 10 & \\
\hline Moderate & 72 & 7 & 19 & 17 & 29 & & 28 & 13 & 15 & 16 & \\
\hline Poorly & 18 & 3 & 2 & 4 & 9 & & 8 & 1 & 6 & 3 & \\
\hline Albumin & & & & & & 0.677 & & & & & 0.332 \\
\hline$\leq 3.5$ & 64 & 8 & 13 & 18 & 25 & & 22 & 14 & 13 & 14 & \\
\hline$>3.5$ & 63 & 8 & 12 & 15 & 28 & & 31 & 6 & 13 & 13 & \\
\hline Total bilirubin (mg/dL) & & & & & & 0.458 & & & & & 0.596 \\
\hline$\leq 1$ & 67 & 10 & 15 & 14 & 28 & & 31 & 8 & 12 & 15 & \\
\hline$>1$ & 67 & 6 & 13 & 19 & 29 & & 25 & 13 & 16 & 13 & \\
\hline $\operatorname{AFP}(\mathrm{mg} / \mathrm{L})$ & & & & & & 0.642 & & & & & 0.306 \\
\hline$\leq 400$ & 110 & 12 & 24 & 28 & 46 & & 46 & 16 & 26 & 22 & \\
\hline$>400$ & 23 & 2 & 5 & 5 & 11 & & 7 & 4 & 4 & 7 & \\
\hline Cirrhosis & & & & & & 0.165 & & & & & 0.386 \\
\hline No & 45 & 3 & 8 & 13 & 21 & & 18 & 9 & 10 & 6 & \\
\hline Yes & 84 & 13 & 19 & 19 & 33 & & 34 & 12 & 16 & 22 & \\
\hline Metastasis & & & & & & 0.876 & & & & & 0.713 \\
\hline No & 114 & 13 & 25 & 30 & 46 & & 46 & 21 & 20 & 25 & \\
\hline Yes & 11 & 3 & 1 & 1 & 6 & & 5 & 0 & 4 & 1 & \\
\hline Diagnostic & & & & & & 0.120 & & & & & 0.835 \\
\hline $\mathrm{HCC}$ & 42 & 3 & 9 & 6 & 24 & & 19 & 4 & 8 & 10 & \\
\hline $\mathrm{HCC}+\mathrm{HBV}$ & 77 & 11 & 11 & 23 & 32 & & 30 & 12 & 18 & 16 & \\
\hline $\mathrm{HCC}+\mathrm{HCV}$ & 15 & 2 & 6 & 4 & 3 & & 6 & 5 & 2 & 3 & \\
\hline $\mathrm{HCC}+\mathrm{HBV}+\mathrm{HCV}$ & 3 & 0 & 2 & 0 & 1 & & 2 & 0 & 1 & 0 & \\
\hline Virus infection & & & & & & 0.065 & & & & & 0.762 \\
\hline No & 44 & 3 & 9 & 7 & 25 & & 20 & 5 & 8 & 10 & \\
\hline Yes & 93 & 13 & 19 & 26 & 35 & & 37 & 16 & 21 & 19 & \\
\hline
\end{tabular}

-, Negative staining; +, weakly positive staining; ++ , moderately positive staining; +++ , strongly positive staining. 
Table 3. Correlation between expression of DLL4 and JAG1 and clinicopathological parameters in HCC patient without virus infection.

\begin{tabular}{|c|c|c|c|c|c|c|c|c|c|c|c|}
\hline \multirow{2}{*}{$\begin{array}{c}\text { Total }(\mathrm{n}=42) \\
\text { HCC without virus } \\
\text { infection }\end{array}$} & \multirow{2}{*}{$n$} & \multicolumn{4}{|c|}{ DLL4 } & \multirow{2}{*}{$P$ value } & \multicolumn{4}{|c|}{ JAG1 } & \multirow{2}{*}{$P$ value } \\
\hline & & - & + & ++ & +++ & & - & + & ++ & +++ & \\
\hline Age (yr) & & & & & & 0.212 & & & & & 0.065 \\
\hline$\leq 60$ & 11 & 0 & 2 & 1 & 8 & & 2 & 0 & 5 & 3 & \\
\hline$>60$ & 31 & 3 & 7 & 5 & 16 & & 17 & 4 & 3 & 7 & \\
\hline Gender & & & & & & 0.411 & & & & & 0.833 \\
\hline Male & 33 & 2 & 20 & 10 & 1 & & 15 & 3 & 7 & 8 & \\
\hline Female & 9 & 2 & 0 & 0 & 7 & & 4 & 1 & 1 & 2 & \\
\hline Tumor size $(\mathrm{cm})$ & & & & & & 0.067 & & & & & 0.446 \\
\hline$\leq 5$ & 17 & 2 & 2 & 0 & 13 & & 10 & 1 & 2 & 4 & \\
\hline$>5$ & 20 & 1 & 7 & 5 & 7 & & 7 & 3 & 4 & 4 & \\
\hline Differentiation & & & & & & 0.317 & & & & & 0.742 \\
\hline Well & 13 & 0 & 2 & 1 & 10 & & 6 & 0 & 4 & 3 & \\
\hline Moderate & 23 & 2 & 5 & 4 & 12 & & 10 & 3 & 3 & 7 & \\
\hline Poorly & 4 & 1 & 0 & 1 & 2 & & 2 & 1 & 1 & 0 & \\
\hline Albumin & & & & & & 0.705 & & & & & $0.043^{*}$ \\
\hline$\leq 3.5$ & 15 & 1 & 3 & 3 & 8 & & 3 & 2 & 3 & 5 & \\
\hline$>3.5$ & 21 & 2 & 3 & 3 & 13 & & 13 & 1 & 5 & 3 & \\
\hline Total bilirubin (mg/dL) & & & & & & 0.880 & & & & & 0.132 \\
\hline$\leq 1$ & 23 & 2 & 6 & 2 & 13 & & 13 & 2 & 4 & 4 & \\
\hline$>1$ & 17 & 1 & 3 & 4 & 9 & & 5 & 2 & 4 & 5 & \\
\hline AFP (mg/L) & & & & & & 0.478 & & & & & 0.885 \\
\hline$\leq 400$ & 31 & 2 & 6 & 5 & 18 & & 14 & 2 & 7 & 7 & \\
\hline$>400$ & 7 & 0 & 3 & 1 & 3 & & 3 & 1 & 1 & 2 & \\
\hline Cirrhosis & & & & & & 0.884 & & & & & 0.542 \\
\hline No & 20 & 2 & 4 & 3 & 11 & & 9 & 3 & 4 & 3 & \\
\hline Yes & 18 & 1 & 4 & 3 & 10 & & 8 & 1 & 2 & 6 & \\
\hline Metastasis & & & & & & 0.975 & & & & & 0.815 \\
\hline No & 33 & 2 & 9 & 5 & 17 & & 15 & 4 & 5 & 8 & \\
\hline Yes & 3 & 1 & 0 & 0 & 2 & & 1 & 0 & 1 & 0 & \\
\hline
\end{tabular}

-, Negative staining; + , weakly positive staining; ++ , moderately positive staining; +++ , strongly positive staining. 
The association of JAG1 and DLL4 expression with time to relapse

We further explored the possibility that JAG1 and DLL4 expression might be associated with disease progressions such as relapse and survival. The patient clinical charts were reviewed retrospectively. We were able to obtain the relapse data from ninety-five patients. However, since most of the patients with relapse were referred back to their primary care hospital or loss follow up from our hospital which is a tertiary care hospital, we did not have the information on the time of death and could not perform the survival analysis. Out of the ninety-five patients, sixty-five percent (65\%) patients developed relapse. We analyzed factors that might be related to tumor relapse and was able to confirm that the presence of metastasis, tumor size more than $5 \mathrm{~cm}$, and poor tumor differentiation were significantly associated with relapse ( $P<0.001, P=0.038$, and $P=0.048$, respectively) (Table 4). As for JAG1 and DLL4 expression, there was no statistically significant association with tumor relapse (Figure 2). Besides the analysis to all expression level, we also analyzed by grouping into low expression level (expression score 0-I) and high expression level (expression score II-III). Interestingly, there was a tendency of negative association between DLL4 expression and tumor relapse, although it did not reach the statistically significant level (Figure 2).

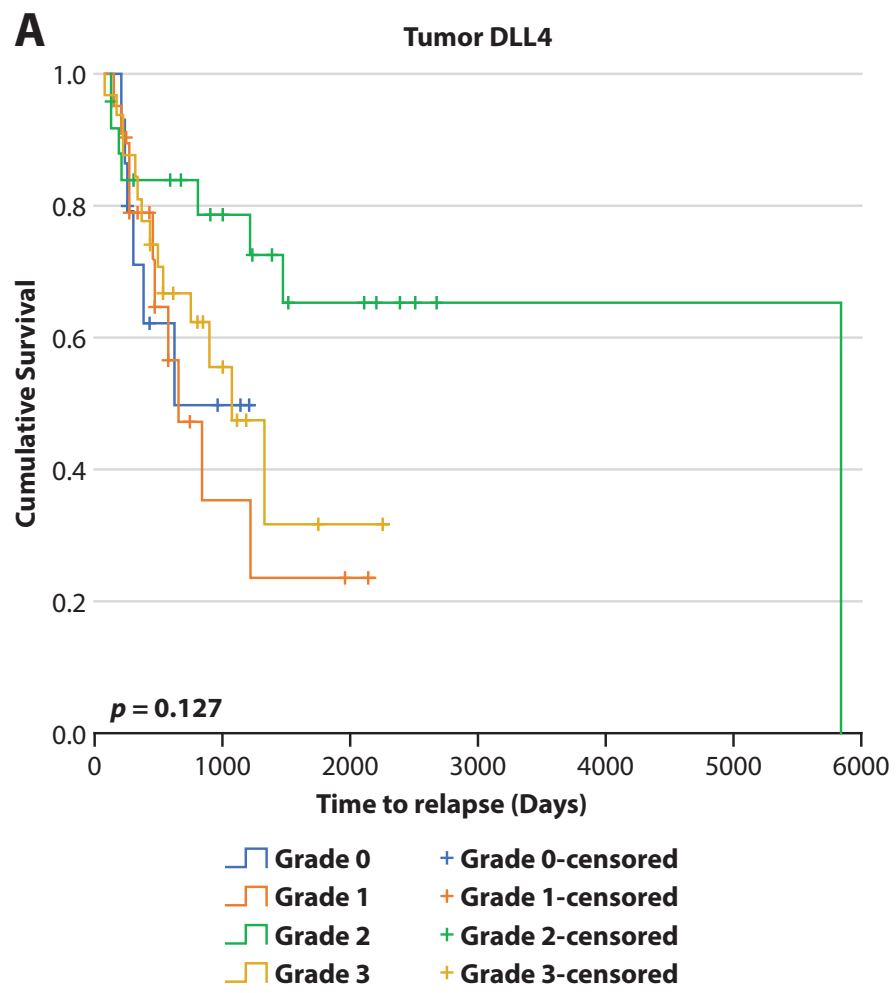

Table 4. The relationship between time to relapse of HCC patient with a clinical parameter.

\begin{tabular}{|c|c|c|}
\hline Clinicopathological parameters & $n$ & $P$ value \\
\hline Tumor Differentiation & & $0.048^{\star * * *}$ \\
\hline Well & 20 & \\
\hline Moderate & 56 & \\
\hline Poorly & 13 & \\
\hline Tumor size $(\mathrm{cm})$ & & $0.038^{* * * *}$ \\
\hline$\leq 5$ & 48 & \\
\hline$>5$ & 47 & \\
\hline Cirrhosis & & 0.767 \\
\hline No & 28 & \\
\hline Yes & 66 & \\
\hline Metastasis & & $<0.001^{* * * *}$ \\
\hline No & 86 & \\
\hline Yes & 6 & \\
\hline $\operatorname{AFP}(\mathrm{mg} / \mathrm{L})$ & & 0.579 \\
\hline$\leq 400$ & 76 & \\
\hline$>400$ & 13 & \\
\hline
\end{tabular}

B

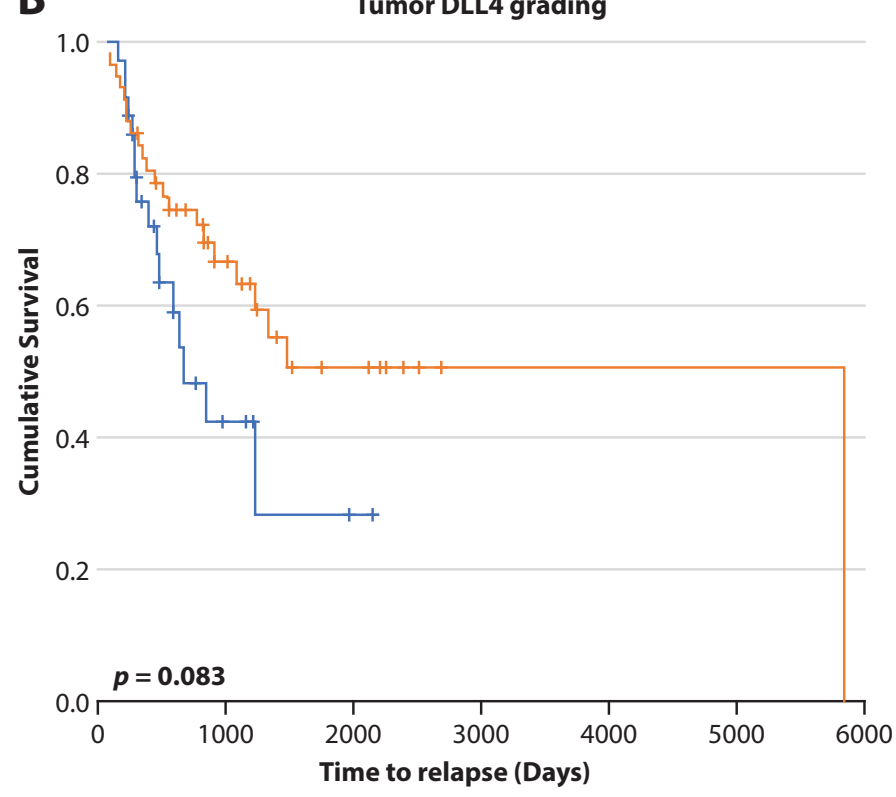

$\neg$ Low DLL4 expression grade 0+1 + Low DLL4 expression-censored $\neg$ High DLL4 expression grade 2+3 + High DLL4 expression-censored

Figure 2. The relationship between time to relapse of HCC patient with the expression level of DLL4 and JAG1. Panel A and $\mathrm{C}$ is the analysis of all expression level of DLL4 and JAG1, respectively. Panel B and D analyzed by grouping into low expression level (expression score 0-I) and high expression level (expression score II, III) of DLL4 and JAG1, respectively. 

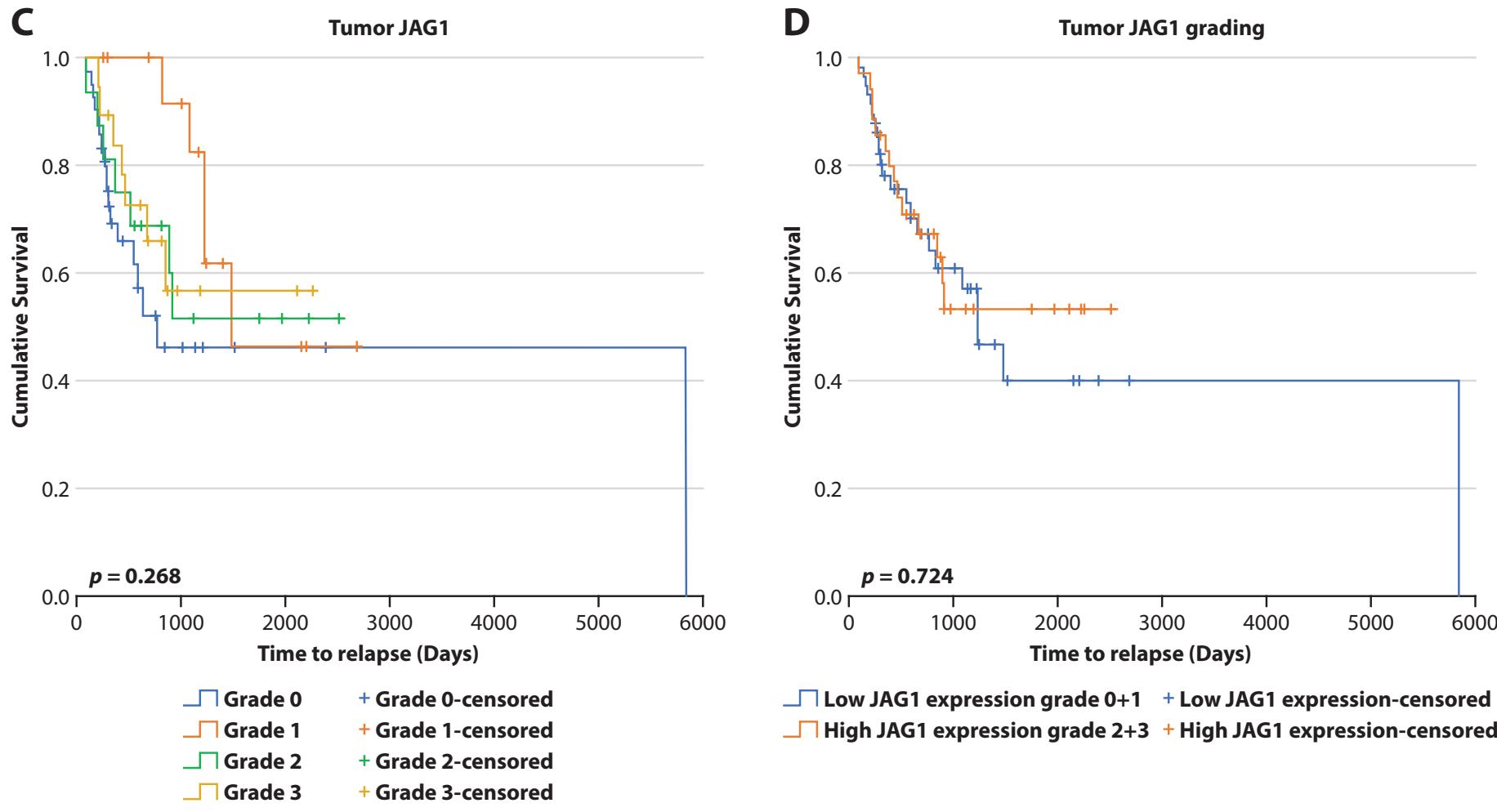

$\square$ Low JAG 1 expression grade 0+1 + Low JAG 1 expression-censored
$-\sqcap$ High JAG 1 expression grade $2+3$ + High JAG 1 expression-censored

Figure 2. The relationship between time to relapse of HCC patient with the expression level of DLL4 and JAG1. Panel A and $\mathrm{C}$ is the analysis of all expression level of DLL4 and JAG1, respectively. Panel B and D analyzed by grouping into low expression level (expression score 0-I) and high expression level (expression score II, III) of DLL4 and JAG1, respectively.

\section{Discussion}

Over the last few decades, Notch signaling has been linked to many cancers. A lot of studies and clinical data support that dysregulation of Notch plays a role in oncogenesis or tumor suppressor depending on a type of cancer. ${ }^{11}$ The first evidence of Notch involvements in an oncogenic role in cancer came from the study of T-cell acute lymphoblastic leukemia (T-ALL). The translocation of Notch1 and $\mathrm{T}$ cell receptor beta (TGB) locus cause the active ICN in leukemia patients. ${ }^{12}$ The induction of Notch1 mutation found in more than $50 \%$ case of T-ALL. ${ }^{13}$ In a solid tumor, constitutive Notch pathway expression by increased of Notch receptor/ligand associated with tumor development including pancreatic cancer, prostate cancer, breast cancer, cervical cancer, and colon cancer. ${ }^{14,15}$ However, the activation of Notch was also reported as tumor suppressor. $^{7}$ A recent report showed that the mice with deficiency $\operatorname{Notch}^{(-/)}$in the skin and primary keratinocytes developed basal cell carcinoma-like (BCC-like) tumors, caused by increased Gil2 expression and $\beta$-catenin signaling. ${ }^{16}$ Furthermore, lack of Notch1 expression results in susceptibility to chemical-induced skin carcinogenesis. ${ }^{16}$ In human skin, Notch signaling is upregulated in normal adult epidermis compared to differentiated cells in basal cell carcinoma, psoriasis and wound healing assay. ${ }^{17}$ The up-regulation of Notch target genes in normal skin reduced the hyperplasticity of the epidermis after phototherapeutic treatment of psoriatic plaques. ${ }^{17}$ The role of Notch signaling in liver cancer remains controversial. Villanueva and colleagues showed that overexpression of intracellular domain of Notch (ICN) induces tumor formation in nude mice through co-overexpressed with Insulin growth factor2 (IGF2) that correlated with HCC development. ${ }^{18}$ However, Qi and colleagues demonstrated that overexpression of (ICN) inhibit HCC growth both in vitro and in vivo by $\mathrm{G}_{0} / \mathrm{G}_{1}$ cell cycle arrest, decreased cyclin $\mathrm{A}$, cyclin D1, cyclin E and upregulated p21, p53. ${ }^{19}$ In Notch1-deficient mice, the liver mice develop the nodular regeneration and hyperplasia and activate spontaneous proliferation in the hepatocyte. ${ }^{20}$ Moreover, increasing of ICN1 inhibit HCC proliferation in triple knockout RB family mice during tumor progression. They were also report that the expression of Notch genes correlated with HCC patient survival. ${ }^{21}$ In this study, we demonstrated that JAG1 is significantly increased in HCC patients compared to adjacent non-tumor hepatocytes. These data were consistent with other studies. ${ }^{9,22}$ High expressed JAG1 were associated with HCC patients with age < 60 years old and low albumin level $(\leq 3.5)$ in non-viral associated HCC. Some study demonstrated that hepatitis B surface antigen carrier rate, and large-sized tumors were associated with younger patients. ${ }^{23,24}$ We did not see this association in this study. We hypothesize that the contribution of Notch signaling differs between viral and non-viral HCC. It is possible that in non-viral associated HCC, high expression of JAG1 might contribute to earlier onset of disease. However, it remains to be confirmed in study with larger sample size. The albumin level is a marker for chronic hepatocellular damage which impaired albumin synthesis. Some report has shown that JAG1 is strongly upregulated in injury cell suggesting that Notch is important in liver regeneration and repair. ${ }^{25}$ Alagille syndrome (AGS) patients is an autosomal dominant 
development disorder which causes by JAG1 mutation. ${ }^{26,27}$ The expression level of JAG1 affects hepatocyte growth factor genes (HFG) that correlate with severity of liver defect in AGS. $^{28}$ In the previous report, JAG1 was shown to correlate with HBx in HCC patients with HBV infection, and significantly increased in tumor well differentiation grade. ${ }^{22}$ However, in this study, we could not confirm those findings. Altogether, accumulating results supported the role of JAG1 as an oncogene in liver cancer. Evidence of an oncogenic role of JAG1 has also been reported in brain cancer, pancreatic cancer, prostate cancer, and cervical cancer. ${ }^{1}$

DLL4 is another Notch ligands that have a controversial role as both oncogenic and tumor suppressive function in T-cell acute lymphoblastic leukemia (T-ALL) and acute myelogenous leukemias (AMLs). ${ }^{29,30}$ In the hepatocellular carcinoma, the role of DLL4 is unknown. Many researches focused on the DLL4 expression in the endothelial cell. ${ }^{31}$ In this study, we reported that DLL4 was also expressing in a cytoplasmic of normal hepatocytes and HCC similar to what has been reported in the Human Protein Atlas Tissue Atlas and Cancer Atlas (http://proteinatlas.org). In general, DLL4 expression was not significantly associated with any clinical parameters. Interestingly, the expression level of DLL4 was significantly lower in tumor tissues than adjacent non-tumor tissues. Moreover, the decreased DLL4 expression in the HCC compared to neighboring tissues tends to associate with tumors with a viral infection, increased tumor size (in non-viral associated HCC), and a higher rate of tumor relapse. Another recent study also showed that DLL4 was mainly expressed in the cytoplasm and cytoplasmic membrane of hepatocellular carcinoma and adjacent non-tumor HCC tissues, respectively. The low level of cytoplasmic DLL4 was significantly associated with tumor metastasis. ${ }^{32}$ However, the mechanism and the role of cytoplasmic DLL4 in the hepatocyte cytoplasm is still unclear. Interestingly, previous evidences also showed that DLL4 can be detected in the cytoplasm of human endometri$\mathrm{um}^{33}$ and luteal cell of pregnant rat. ${ }^{34}$ The diffuse pattern of DLL4 was suggested to be the result of proteolytic degradation after receptor binding. ${ }^{33}$ It is possible that aberrant DLL4 expression in the hepatocyte might be the result of degradation as well; however, further study is needed. In addition, DLL4 is Notch ligand expressing in an endothelial cell that important for vasculature development and critical in angiogenesis for many cancers. The expression of DLL4 in endothelial cell show a tumor-suppressive function by inhibiting of neighboring non-small cell lung cancer (NSCLC) cells proliferation. ${ }^{35}$ DLL4 has also been protecting liver damage by downregulating chemokine during in vitro study of liver fibrosis in kupffer and hepatic stellate cells. ${ }^{36}$

The role of Notch signaling in hepatocellular carcinoma is strongly controversial depend on the content of tumor microenvironment. Interestingly, in this study we observed that JAG1 and DLL4 expressed in HCC might have an inverse function as oncogenic and tumor suppressor. The Notch1 and Notch2 expression have also been reported to have contrasting role in tumor differentiation of human breast cancer tissues. ${ }^{37}$ A recent study has suggested that DLL4 and JAG1 have opposite effects in angiogenesis switch. ${ }^{38}$ The overexpression of JAG1 or inhibition of DLL4 leads to increased vessel density of endothelial cell. ${ }^{39}$ Accumulating evidence shows that constitutive Notch expression or loss of Notch function may have multiple functions in cancer initiation, tumor progression or tumor suppressive. In conclusion, this observation supported the role of JAG1 as an oncogene Interestingly, the pattern of DLL4 expression in adjacent tumor tissue is different from tumor tissue. We hypothesized that DLL4 might change the localization pattern or isoform in the tumor cell. Moreover, the staining pattern of DLL4 may be used as a confirmatory marker to separate HCC from non-tumor cells by immunohistochemistry.

\section{Conflicts of Interest}

The authors declare that there is no conflict of interest regarding the publication of this article.

\section{Acknowledgements}

This study was supported by National Research Council of Thailand 2013 and the Ratchadaphiseksomphot Matching Fund from the Faculty of Medicine, Chulalongkorn University; International Research Integration, Chula Research Scholar, Ratchadaphisek somphot Endowment Fund, Center of Excellence in Immunology and Immune-mediated Diseases and the Rachadapisaek Sompote Post-Doctoral Fund, Chulalongkorn University.

\section{References}

1. Leong KG, Karsan A. Recent insights into the role of Notch signaling in tumorigenesis. Blood. 2006;107(6):2223-33.

2. Simonetti RG, Camma C, Fiorello F, Politi F, D’Amico G, Pagliaro L. Hepatocellular carcinoma. A worldwide problem and the major risk factors. Dig Dis Sci. 1991;36(7):962-72.

3. Llovet JM, Ricci S, Mazzaferro V, Hilgard P, Gane E, Blanc JF, et al. Sorafenib in advanced hepatocellular carcinoma. N Engl J Med. 2008;359(4):378-90.

4. Kopan R, Ilagan MX. The Canonical Notch Signaling Pathway: Unfolding the Activation Mechanism. Cell. 2009;137(2):216-33.

5. Weerkamp F, van Dongen JJ, Staal FJ. Notch and Wnt signaling in T-lymphocyte development and acute lymphoblastic leukemia. Leukemia. 2006;20(7):1197-205

6. Takebe N, Nguyen D, Yang SX. Targeting notch signaling pathway in cancer: clinical development advances and challenges. Pharmacol Ther. 2014;141(2):140-9.

7. Dotto GP. Notch tumor suppressor function. Oncogene. 2008;27(38): 5115-23.

8. Gao J, Song Z, Chen Y, Xia L, Wang J, Fan R, et al. Deregulated expression of Notch receptors in human hepatocellular carcinoma. Dig Liver Dis. 2008; 40(2):114-21

9. Nijjar SS, Wallace L, Crosby HA, Hubscher SG, Strain AJ. Altered Notch ligand expression in human liver disease: further evidence for a role of the Notch signaling pathway in hepatic neovascularization and biliary ductular defects. Am J Pathol. 2002;160(5):1695-703.

10. Dufraine J, Funahashi Y, Kitajewski J. Notch signaling regulates tumor angiogenesis by diverse mechanisms. Oncogene. 2008;27(38):5132-7.

11. Rizzo P, Osipo C, Foreman K, Golde T, Osborne B, Miele L. Rational targeting of Notch signaling in cancer. Oncogene. 2008;27(38):5124-31.

12. Ellisen LW, Bird J, West DC, Soreng AL, Reynolds TC, Smith SD, et al. TAN-1, the human homolog of the Drosophila notch gene, is broken by chromosomal translocations in T lymphoblastic neoplasms. Cell. 1991; 66(4):649-61.

13. Weng AP, Ferrando AA, Lee W, Morris JPt, Silverman LB, Sanchez-Irizarry $\mathrm{C}$, et al. Activating mutations of NOTCH1 in human $\mathrm{T}$ cell acute lymphoblastic leukemia. Science. 2004;306(5694):269-71.

14. Callahan R, Egan SE. Notch signaling in mammary development and oncogenesis. J Mammary Gland Biol Neoplasia. 2004;9(2):145-63. 
15. Gray GE, Mann RS, Mitsiadis E, Henrique D, Carcangiu ML, Banks A, et al. Human ligands of the Notch receptor. Am J Pathol. 1999;154(3):785-94.

16. Nicolas M, Wolfer A, Raj K, Kummer JA, Mill P, van Noort M, et al. Notch1 functions as a tumor suppressor in mouse skin. Nature Genet. 2003; 33(3):416-21.

17. Thelu J, Rossio P, Favier B. Notch signalling is linked to epidermal cell differentiation level in basal cell carcinoma, psoriasis and wound healing. BMC Dermatol. 2002;2:7.

18. Villanueva A, Alsinet C, Yanger K, Hoshida Y, Zong Y, Toffanin S, et al. Notch signaling is activated in human hepatocellular carcinoma and induces tumor formation in mice. Gastroenterology. 2012;143(6): 1660-9 e7.

19. Qi R, An H, Yu Y, Zhang M, Liu S, Xu H, et al. Notch1 signaling inhibits growth of human hepatocellular carcinoma through induction of cell cycle arrest and apoptosis. Cancer Res. 2003;63(23):8323-9.

20. Croquelois A, Blindenbacher A, Terracciano L, Wang X, Langer I, Radtke F, et al. Inducible inactivation of Notch1 causes nodular regenerative hyperplasia in mice. Hepatology. 2005;41(3):487-96.

21. Viatour P, Ehmer U, Saddic LA, Dorrell C, Andersen JB, Lin C, et al. Notch signaling inhibits hepatocellular carcinoma following inactivation of the RB pathway. J Exp Med. 2011;208(10):1963-76.

22. Gao J, Chen C, Hong L, Wang J, Du Y, Song J, et al. Expression of Jagged1 and its association with hepatitis $\mathrm{B}$ virus $\mathrm{X}$ protein in hepatocellular carcinoma. Biochem Biophys Res Commun. 2007;356(2):341-7.

23. Ou LH, Chau GY, Tsay SH, Chiu JH, Wu JC, King KL, et al. Clinicopathological comparison of respectable hepatocellular carcinoma between the young and the elderly patients. Chin Med J. 1997;60:40-7.

24. Tsai FC, Liu CJ, Chen CL, Chen PJ, Lai MY, Kao JH, et al. Lower serum viral loads in young patients with hepatitis B virus-related hepatocellular carcinoma. J Viral Hepat. 2007;14:153-60.

25. Morell CM, Strazzabosco M. Notch signaling and new therapeutic options in liver disease. J Hepatol. 2014;60(4):885-90.

26. Li L, Krantz ID, Deng Y, Genin A, Banta AB, Collins CC, et al. Alagille syndrome is caused by mutations in human Jagged1, which encodes a ligand for Notch1. Nature Genet. 1997;16(3):243-51.

27. Oda T, Elkahloun AG, Pike BL, Okajima K, Krantz ID, Genin A, et al. Mutations in the human Jagged1 gene are responsible for Alagille syndrome. Nature Genet. 1997;16(3):235-42.
28. Yuan ZR, Kobayashi N, Kohsaka T. Human Jagged 1 mutants cause liver defect in Alagille syndrome by overexpression of hepatocyte growth factor. J Mol Biol. 2006;356(3):559-68.

29. Tohda S, Murata-Ohsawa M, Sakano S, Nara N. Notch ligands, Delta-1 and Delta-4 suppress the self-renewal capacity and long-term growth of two myeloblastic leukemia cell lines. Int J Oncol. 2003;22(5):1073-9.

30. Yao J, Qian C. Over-activated Notch-1 protects gastric carcinoma BGC-823 cells from TNFalpha-induced apoptosis. Dig Liver Dis. 2009;41(12):867-74.

31. Shutter JR, Scully S, Fan W, Richards WG, Kitajewski J, Deblandre GA, et al. Dll4, a novel Notch ligand expressed in arterial endothelium. Genes Dev. 2000;14(11):1313-8.

32. Chen H, Yang L, Zang S, Zhuo L, Fang X, Zhang Y, et al. High level of Delta-like ligand 4 suppresses the metastasis of hepatocellular carcinoma. Int J Clin Exp Pathol. 2016;9(3):2989-97.

33. Mazella J, Liang S, Tseng L. Expression of Delta-Like Protein 4 in the Human Endometrium. Endocrinology. 2008;149(1):15-9.

34. Hernandez F, Peluffo MC, Stouffer RL, Irusta G, Tesone M. Role of the DLL4-NOTCH System in PGF2alpha-Induced Luteolysis in the Pregnant Rat. Biol Reprod. 2011;84:859-65.

35. Ding XY, Ding J, Wu K, Wen W, Liu C, Yan HX, et al. Cross-talk between endothelial cells and tumor via delta-like ligand 4/Notch/PTEN signaling inhibits lung cancer growth. Oncogene. 2012;31(23):2899-906.

36. Shen Z, Liu Y, Dewidar B, Hu J, Park O, Feng T, et al. Delta-Like Ligand 4 Modulates Liver Damage by Down-Regulating Chemokine Expression. Am J Pathol. 2016;186(7):1874-89.

37. Parr C, Watkins G, Jiang WG. The possible correlation of Notch-1 and Notch-2 with clinical outcome and tumour clinicopathological parameters in human breast cancer. Int J Mol Med. 2004;14(5):779-86.

38. Benedito R, Roca C, Sorensen I, Adams S, Gossler A, Fruttiger M, et al. The notch ligands Dll4 and Jagged1 have opposing effects on angiogenesis. Cell. 2009;137(6):1124-35

39. Pedrosa AR, Trindade A, Fernandes AC, Carvalho C, Gigante J, Tavares AT, et al. Endothelial Jagged1 antagonizes Dll4 regulation of endothelial branching and promotes vascular maturation downstream of Dll4/Notch1. Arterioscler Thromb Vasc Biol. 2015; 35(5):1134-46. 